\title{
Linking Ethical Leadership with Employee Work Outcomes: The Moderating Role of Conscientiousness
}

\author{
Saqib Adnan ${ }^{1}$ \\ Saima Batool ${ }^{2}$ \\ Muhammad Aleem ${ }^{3}$
}

\begin{abstract}
Ethical leadership continues to receive considerable attention due to its influence on various job outcomes, therefore this study was conducted to examine the effect of ethical leadership on job outcomes (employee wellbeing and worker's voice) and to demonstrate that how good faith direct the relationship between ethical leadership and job outcomes. This study was conducted in the Non-Government organizations in Peshawar. Information was gathered from 180 workers working in 6 diverse NGO's in Peshawar. Information was gathered through an organized questionnaire and convenience sampling technique was used. The results of this study showed that ethical leadership was positively related to employee well-being and employee voice. The findings of the study show that there is a strong relationship between ethical leadership, employee voice, employee well-being. The main contribution of this study was to find the significant moderating effect of conscientiousness on both dependent variables. The future implication shows that organizations can identify those aspects through which employee work outcome can be improved. The use of ethical leadership strategies can allow managers to build a positive attitude in employees which results in employee well-being.
\end{abstract}

JEL Classification: $L 31$, M54, M59

Keywords: Ethical Leadership, Employee Well-being, Employee Voice, Conscientiousness.

\section{INTRODUCTION}

The style of leadership followed by the organizations tends to be its key to success and failure. Good and effective leaders tend to have a positive impact on the overall environment of the workplace and teamwork. However, bad leadership not only affect the workplace environment but also results in poor performances of employees, their well-being and increases absenteeism and reduces employee voice and freedom to speak.

Leadership is a contested term with multiple meanings and diverse practical applications. A leader is specifically that person of the organization who directs, motivates and influences others to enhance the performances (Ojokuku, Odetayo, and Sajuyigbe, 2012; Western, 2019). A leader is responsible for inspiring its subordinates towards effective performances in order to attain goals and corporate objectives (Mo, Ling, \& Xie, 2017). Leadership is said to be that process of the organization, which aims to influence others for strong commitment towards the organization by realizing their potential in order to add value within organizational productivity, share their vision, integrity, and passion (Jeremy, Melinde \& Ciller, 2012). Leaders are known for their moral responsibilities, authorities, and activities. Their status is associated with such attributes that represent goodness and virtue, and their specific ability to encourage followers to perform good deeds (Fehr, Yam and Dang 2015). The ethical

1- IBMS, Agriculture University, Peshawar.

2 \& 3 - Department of Management Sciences, Qurtuba University of Science and Information Technology, Peshawar. Email: dr.saimabatoo190@yahoo.com

\begin{tabular}{|c|c|}
\hline ISR-MSSE & Volume 17 \\
\hline
\end{tabular}


environment is an organizational environment where employees are considered, well understood, respected and there is also mutual trust, honesty, and integrity and employees feel that they are part of the organization. The leader that creates such an organizational environment is a leader that reflects ethics and trustworthiness in all his or her behaviors and is faithful to moral values (Barkhordari, Ashktorab, \& Atashzadeh, 2017). Therefore, a leadership style that pays attention to ethical dimensions is needed to improve work outcomes of the employees working in NGOs.

Despite the outstanding importance of ethical leadership, this concept and its consequences have been investigated sporadically. Studies on the outcomes of ethical leadership are mostly quantitative studies that have emphasized the relationship between ethical leadership and the variables that may have an impact on them. Studies of the same nature in NGOs are needed to have a clearer perspective and a basis to discuss and reflect the special patterns in such organizations (Barkhordari, et.al, 2017).

Numerous studies have been conducted on ethical leadership and its impact on employee outcome and the role of consciousness; however, limited investigation is done to establish the link between ethical leadership, job-related outcome, consciousness and employee voice (Hassan et al., 2014; Chughtai et al., 2015; Hoch, Bommer, Dulebohn, \& Wu, 2018; Western, 2019). When the employee is asked to raise their voices then it is easier to enhance the organizational output because of numerous ideas and recommendations.

Different studies have discussed each dimension separately in link to ethical leadership, but these dimensions were not altogether discussed in any research earlier. Hence, this study focused on identifying and addressing the gap in previous studies related to the link between ethical leadership, employee wellbeing, employee voice and role of consciousness as a moderator in this relationship.

The aim of this research is to investigate the relationship of ethical leadership with employee work outcome and the moderating role of consciousness. It further aimed to investigate the contribution of employee well-being, employee voice and employee work-related outcomes based on the ethical leadership within the organizations. Furthermore, the study focused on Pakistani NGOs work environment context. Based on this, the objectives of the study are:

1. To examine the effect of ethical leadership on employee well-being.

2. To find out the effect of ethical leadership on employee voice.

3. To examine the moderating role of conscientiousness on the relationship between ethical leadership and employee well-being.

4. To examine the moderating role of conscientiousness on the relationship between ethical leadership and employee voice.

\section{LITERATURE REVIEW}

Numerous studies have discussed different characteristics of leadership and its effect on employee's productivity and performance. Leaders choose diverse styles and approach to coordinate, communicate, and deal with the employees (Mehilic, Lipicnik, \& Tekavcic, 2010; Bavik, Tang, Shao, \& Lam, 2018). Analyzing the literature, it has been seen that various researchers have highlighted different aspects of leadership (Watson, 2010; Hoch, et.al, 2018). Their role, responsibilities, and influence have been studied considering different factors that 
influence the overall performance of employees. Strong leadership plays an effective role in enhancing an employee's work performance and outcomes. The leaders believe in forming work relationships with their employees and play a moderating role throughout their work (Xhang, Walumbwa, Aryee, \& Chen, 2013). The management research has closely analyzed and evaluated the role and responsibilities of leaders working at different levels and how they influence the performance of employees. The literature does not provide enough information on ethical leadership and its relationship with the employee work outcomes.

Standards and Ethics get down to business the life of people and help them in contrasting amongst wrong and right and, great and awful. Morals give people, organizations, and groups with an arrangement of standards and rules looking after the way of life, customs, religion, standards, and qualities. (Ritch \&Mengel, 2009; Babalola, Stouten, Euwema, \& Ovadje, 2018). Leaders are the ones who are supposed to lead organizations according to the set of values, principles, and guidelines. The leadership standards are an arrangement of rules as indicated by which the leaders lead their subordinates (Akker, Heres, Lastuizen, \&Six, 2009). Identifying and following ethical principles is a challenge for leaders. If they fail to work and lead ethically it will result in creating more unethical followers. To choose the right ways, it is important to analyze and evaluate the situation (Hazy, 2008). The problems should be discussed and shared with the concerned authorities and individuals. Alternatives should be considered and then decisions should be taken. Ethical Leadership is based on the thought of leaders possessing skills and abilities, which allows them to work ethically and lead their teams and employees using the same ethical guidelines (Derr, 2012).

Ethical leadership is all about building the capacity of the employees. Barkhordari, et.al, 2017 asserts that by creating an ethical climate, ethical leadership leads to positive and effective work outcomes. Therefore, an ethical work environment that supports employee's progress and development can be developed by paying more attention to moralities in recruitment, teaching ethical values to the leaders, and using a systematic and objective approach to assess morality in the environment (Hazy 2008; Babalola, et.al, 2018). Ethical leadership is especially important because respectful and valued behavior in the workplace is central for the willingness and ability of employees to cooperate and avoid escalating conflicts (Zhang, \& Tu, 2016)

\section{Ethical Leadership and Employee Voice}

Ethical leadership may affect an employee's voice (Mo, \& Shi, 2016). Employees are likely to receive more individualized care and support under the supervision of ethical leaders. Subsequently, they are more likely to reciprocate by developing and expressing attitudes valued by their supervisors (Lee, Choi, Youn, \& Chun, 2015; Kremer, Villamor, \& Aguinis, 2019). Employee voice is a form of employees' prosocial behavior aimed at improving existing work practices and procedures instead of working within an ineffective or inefficient status quo. Thus, it is suggested that ethical leadership can enhance an employee's voice for the following two reasons. First, ethical supervisors usually treat employees with care, respect, and fairness (Burris, 2012). As the team's representative, they publicly advocate for the team's ethical values, develop an ethical climate, and reward employees who take the appropriate courses of action. Within this environment, the employee's concerns about the potential risks of speaking up are largely minimized. They are more likely to identify with the supervisor and the focal team and as a result make proactive suggestions regarding not only team ethics but also innovative methods and procedures that enhance team efficiency (Mo, \& Shi, 2016).

\begin{tabular}{llll}
\hline JISR-MSSE & Volume 17 & Number 1 & January-June 2019 \\
\hline 185
\end{tabular} 
Second, ethical supervisors tend to provide team employees with virtuous resources, such as collective trust, in addition to psychological and physical support. With such resources, employees are more able to implement new ideas that are potentially beneficial to the collective. That is, when they realize that the current work processes and procedures can be further improved, they are more likely to reciprocate with constructive suggestions for the team (Burris, 2012). Therefore, it is proposed that ethical leadership can positively enhance an individual employee's voice targeted at the team. Despite the general expectation that ethical leadership fosters employees' ethical behaviors, surprisingly little empirical effort has been made to verify this expected effect of ethical leadership (Lee, et.al, 2015; Peng, \& Wei, 2019). To address this research gap, this study will examine the role of ethical leadership in relation to an employee's voice. Therefore, it is hypothesized that:

Hypothesis 1: Ethical leadership is positively related to employee voice.

\section{Ethical Leadership and Employee Well-Being}

Happiness and the worthiness of human life, what we call well-being, reflects the Aristotelian concept of eudemonia: "Aristotle's view of human happiness that assesses the goodness of life-based on living in a manner that actively expresses the excellence of character or virtue is eudemonic wellbeing" (Haybron, 2000, p. 210). It is experienced when one feels intensive involvement, special fit with activity, and intensively alive. In this sense, eudemonia occurs when one is fully engaged in an activity and existing as one's true self. Therefore, eudemonic engagement assumes introspective reflection upon one's values and reasoned choices for engagement in specific activities, and not only hedonic motivation. (Ilies, Morgeson, \& Nahrgang, 2005; Luu, 2019). "Employee well-being has been characterized as the positive affective states associated with happiness and meaningfulness at work and has been found to be positively related to maintaining quality relationships and work performance" (Avey, Wernsing, \& Palanski, 2012; p. 25). Zhang, \& Tu, (2016) investigated the cross-domain effects of ethical leadership on employees' family and life satisfaction and wellbeing. Drawing on the work-family enrichment theory, it focused on the relationship between ethical leadership and employees' family and life satisfaction and wellbeing. They found a strong relationship between the study variables.

Ethical leaders are likely to impact employees' well-being through indirect and direct behaviors that affect employees' emotions. For example, ethical leadership is concerned with upholding normative values, doing the right thing, and role modeling moral behaviors for employees. Since leaders shape employee perceptions and meanings associated with their work (Smircich and Morgan 1982), employees working with more ethical leaders may perceive their work experiences as fairer and their tasks as more meaningful (Avey, et.al, 2012; p. 25). Fundamentally, ethical leadership is leading in a way that respects the rights and dignity of people. Employees working with ethical leaders experience more positive affective states of satisfaction and happiness due to higher quality relationships and ethical work norms (Luu, 2019). Therefore, it is proposed that:

Hypothesis 2: Ethical leadership is positively related to employee well-being. 


\section{Moderating Role of Conscientiousness}

Conscientiousness has typically been conceptualized as an individual-level trait. Individual-level conscientiousness reflects the norms, habits, and routines that characterize employee behavior. Walumbwa, Morrison, and Christensen, (2012) argued that ethical leaders display behaviors such as honesty, responsibility, reliability, and truthfulness, which they argue are "hallmarks of conscientiousness". In other words, they suggested a link between the behaviors that are central to ethical leadership and those that convey high conscientiousness, both with respect to ethical conduct (Babalola, Bligh, Ogunfowora, Guo, \& Garba, 2019). If a leader displays behaviors signaling dependability, self-discipline, responsibility, and high standards, the group is likely to develop norms consistent with these characteristics (Greco, Whitson, O'Boyle, Wang, \& Kim, 2019). Ethical leaders, through their behavior (and in particular, their display of self-discipline, responsibility, and reliability), convey cues that signal high levels of conscientiousness, which the group will internalize (Kaptein, 2019). Reciprocity is also likely to explain why ethical leadership will foster higher group-level conscientiousness. Building from social exchange theory (Blau, 1964), Brown and Treviño (2006) suggested that employees will be motivated to reciprocate the fair treatment that they receive from ethical leaders (Greco, et.al 2019). One way in which they might do so is by exhibiting high levels of dependability, effort, and diligence - in other words, conscientiousness (Hofmann \& Jones, 2005). In sum, it is proposed that ethical leadership together with conscientiousness will foster employee voice and employee wellbeing. Therefore, it is hypothesized that:

Hypothesis 3: Conscientiousness moderates the relationship between ethical leadership and employee voice.

Hypothesis 4: Conscientiousness moderates the relationship between ethical leadership and employee wellbeing.

\section{THEORETICAL FRAMEWORK}

The theoretical framework of the present study is given in figure 1. The theoretical framework of the current study included one independent variable; Ethical leadership and two dependent variables; Employee Voice and Employee well-being. It also contains one moderating variable; Conscientiousness. The following figure shows the theoretical framework for this study.

Figure 1: Framework of the study

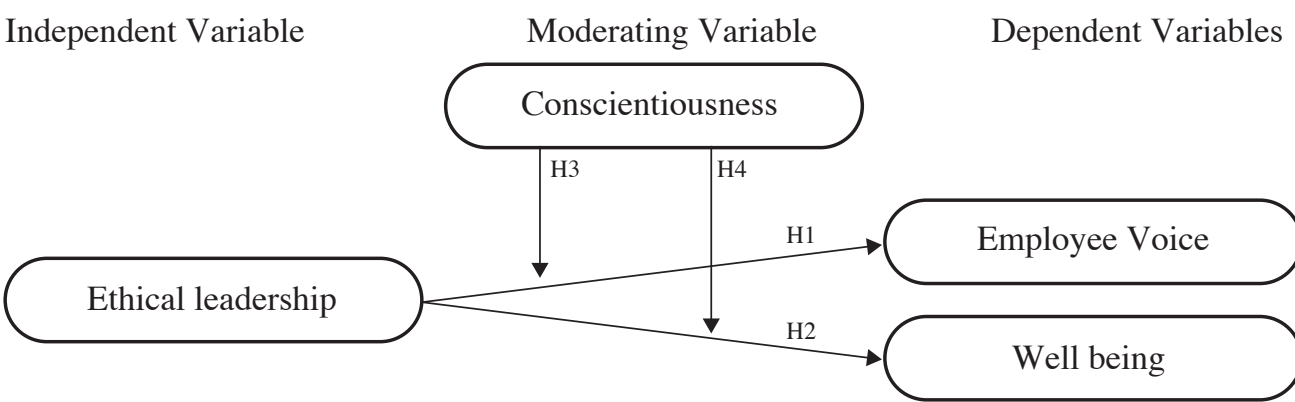




\section{RESEARCH METHODOLOGY}

\section{Population of the Study}

The population of this study was composed of the employees working in the Non-Governmental organizations in Peshawar. However, due to several constraints like time, non-accessibility and financial constraints, the focus of the study was on the target organizations. The target organizations of the study were the employees of 6 Non-Governmental organizations operating in Peshawar. As per information provided by the employees of the organization, approximate numbers of employees working were 700 .

\section{Sampling Design}

Non-probability Sampling was adopted for sampling. Convenience sampling was used as a sampling technique to select a sample for the current study because this technique is appropriate for gaining quick information about a certain phenomenon of interest.

\section{Sample Size/Strategy}

The sample size of this research was of 180 respondents that are working in the non-governmental organization in Peshawar. It was based on Yamane (1967) formula for sampling for defining sample size from the population. The structured questionnaire was prepared which was distributed to employees at different levels, working in various NGOs. The questionnaire was distributed through a personal survey and email. Table 1 shows the sample NGOs selected for the data collection:

\section{Sample Size/Strategy}

The sample size of this research was of 180 respondents that are working in the non-governmental organization in Peshawar. It was based on Yamane (1967) formula for sampling for defining sample size from the population. The structured questionnaire was prepared which was distributed to employees at different levels, working in various NGOs. The questionnaire was distributed through a personal survey and email. Table 1 shows the sample NGOs selected for the data collection:

Table 1

\begin{tabular}{lcc}
\hline Organization & Total Employees & Sample \\
\hline Khwendo Kor (KK) & 122 & 40 \\
Kher Khegara Tanzeem (KKT) & 98 & 30 \\
Pakistan Red Crescent Society & 158 & 31 \\
International Rescue Committee & 156 & 34 \\
Community Development Unit & 80 & 20 \\
Peace \& Development Organization (PADO) & 86 & 25 \\
Total & 700 & 180 \\
\hline
\end{tabular}

\section{Research Instrument}

According to Gravetter and Forzano (2011), research instruments include an interview, questionnaire, observation, and unobtrusive method. Questionnaires are commonly used in quantitative studies. The research instrument selected for this study is a close-ended questionnaire. It was scaled on the 5-point Liker scale. The questionnaire includes the items of variable i.e. ethical leadership, employee well-being, employee voice, and consciousness. 


\section{Data Analysis}

The hypothetical relationship was tested by using regression analysis technique. Both simple and multiple regression analysis was conducted for this study.

The following tests or measured were carried out in the present study.

1. Descriptive statistics

2. Reliability analysis

3. Correlation

4. Simple regression

5. Multiple regression

\section{RESULTS AND DISCUSSION}

\section{Descriptive statistics}

Table 2 is related to the gender of respondents and it shows that most of the respondents i.e. $50.6 \%$ were male and remaining $49.4 \%$ were female. Hence, the above data illustrate that there was a slight difference between male and female respondents contributed to the study.

Table 2. Gender of Respondents

\begin{tabular}{cccccc}
\hline \multicolumn{2}{c}{ Gender } & Frequency & Percent & Valid Percent & Cumulative Percent \\
\hline \multirow{3}{*}{ Valid } & Male & 91 & 50.6 & 50.6 & 50.6 \\
& Female & 89 & 49.4 & 49.4 & 100.0 \\
& Total & 180 & 100.0 & 100.0 & \\
\hline
\end{tabular}

Source: Survey

Age of Respondents

Table 3 is related to the age of respondents and it shows that most of the respondents i.e. $42.8 \%$ belong from the age bracket of 31 to 35 years, $27.8 \%$ respondents belong from 26 to 30 years, $18.3 \%$ belong from 36 and above and remaining $11.1 \%$ belong from 20 to 25 years. Hence, it shows that the majority of respondents belonged from the professional level.

Table 3. Age of Respondents

\begin{tabular}{cccccc}
\hline & Age & Frequency & Percent & Valid Percent & Cumulative Percent \\
\hline \multirow{3}{*}{ Valid } & 20 to 25 Years & 20 & 11.1 & 11.1 & 11.1 \\
& 26 to 30 Years & 50 & 27.8 & 27.8 & 38.9 \\
& 31 to 35 Years & 77 & 42.8 & 42.8 & 81.7 \\
& 36 and above & 33 & 18.3 & 18.3 & 100.0 \\
& Total & 180 & 100.0 & 100.0 &
\end{tabular}

Source: Survey

Working Years of Respondents

The below table uncovers the information accumulated from the question identified with working years of respondents. In light of the below table, it is assembled that larger part respondents i.e. $40.6 \%$ were working in the NGOs from past 4 to 6 years. $28.9 \%$ were working from 7 to 10 years, $21.7 \%$ were working from over 10 years and staying $8.9 \%$ were working from 1 to 3 years. In light of the above table, it is uncovered that the greater part of respondents was working in an organization from 4 to 6 years.

\begin{tabular}{llll}
\hline JISR-MSSE & Volume 17 & Number 1 & January-June 2019 \\
\hline
\end{tabular}


Table 4. Working Years of Respondents

\begin{tabular}{cccccc}
\hline & Working Years & Frequency & Percent & Valid Percent & Cumulative Percent \\
\hline \multirow{3}{*}{ Valid } & 1 to 3 Years & 16 & 8.9 & 8.9 & 8.9 \\
& 4 to 6 Years & 73 & 40.6 & 40.6 & 49.4 \\
& 7 to 10 Years & 52 & 28.9 & 28.9 & 78.3 \\
& More than 10 Years & 39 & 21.7 & 21.7 & 100.0 \\
& Total & 180 & 100.0 & 100.0 & \\
\hline
\end{tabular}

Source: Survey

\section{Regression Analysis}

In order to test the research hypothesis various test was applied. The linear regression analysis was performed in order to analyze the linear relationship between the dependent and independent variable. General regression analysis was performed to analyze the moderating role of consciousness and its impact on work outcome. Pearson correlation test was performed in order to analyze the relationship among variables.

Table 5. Regression Analysis between Ethical Leadership and Employee Well-Being

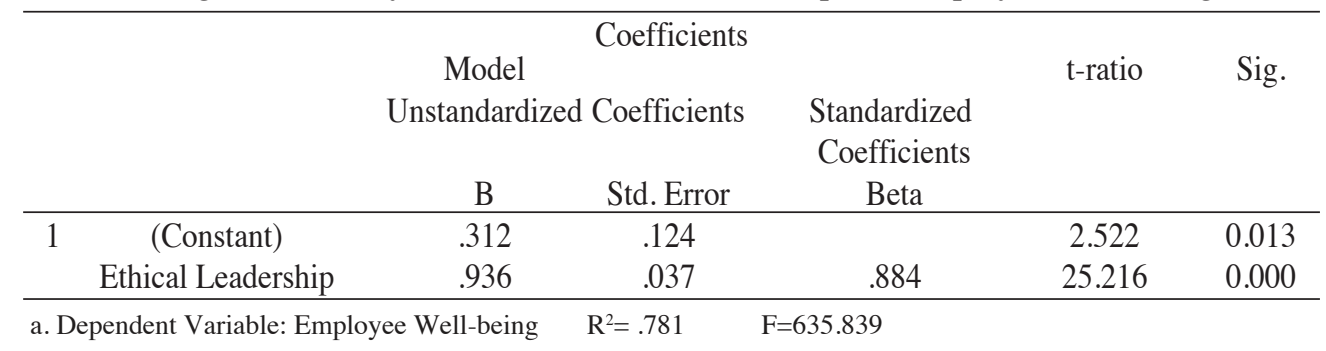

The above table explains the reliance of the dependent variable on the independent variable. In view of the above $\mathrm{R}$ square Value, it is notable that the relationship likelihood is .781, which shows $78 \%$ of the variance in employee well-being. Therefore, through analyzing the sig value the confirmation is done. As the sig value is 0.000 , it means that the alternative hypothesis is accepted and there is a linear relationship among two variables that are employee well-being and ethical leadership. Further, it also validates the study shared by Givens (2008) and shows that when organizations are adopting ethical leadership strategies then they also focus on employee well-being. The value of regression coefficient was .936 this value indicates that per unit increase in Ethical leadership, will bring an increase in employee well-being. Moreover, an alternative hypothesis is accepted because the t-value was 25.216. Therefore, it shows the strong relationship among variable that is employee wellbeing and ethical leadership.

Table 6. Regression Analysis between ethical leadership and Employee Voice

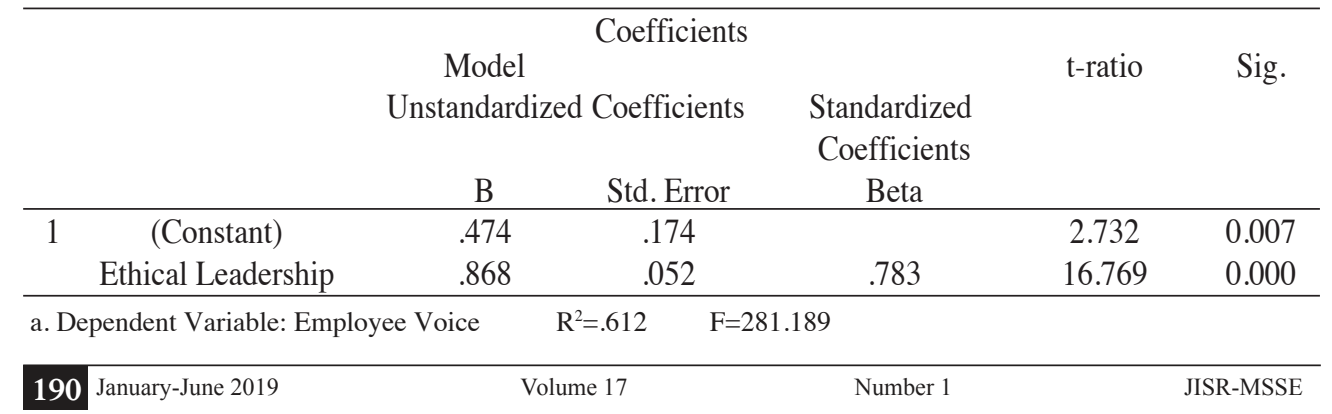


The above table shows R-square value is .612, which shows $61 \%$ variance in employee voice. The sig value is 0.000 , it means that the alternative hypothesis is accepted and there is a linear relationship among two variables that are employee voice and ethical leadership. Further, it also justifies the study shared by Van Dyne and LePine (1998) and proves that in today's era the organizations are adopting ethical leadership practices in order to engage employee at the workplace so that they can share their views openly. In the table, the value of F was 281.189 with $\mathrm{p}=0.000$ which was less than 0.05 and shows that data was fitting overall model. Moreover, the alternative hypothesis is accepted because the t-value was 16.769 and the standard error was. 052. The value of the regression coefficient was .868 this value shows the strong relationship between variables; that is ethical leadership and employee voice.

Table 7 Moderation Effect of Conscientiousness on the Relationship of Ethical Leadership and Employee Well-Being:

\begin{tabular}{|c|c|c|c|c|c|c|}
\hline \multicolumn{7}{|c|}{ Coefficients } \\
\hline & & \multicolumn{2}{|c|}{$\begin{array}{l}\text { Model } \\
\text { Unstandardized Coefficients }\end{array}$} & \multirow{2}{*}{$\begin{array}{c}\text { Standardized } \\
\text { Coefficients } \\
\text { Beta }\end{array}$} & \multirow[t]{2}{*}{ t-ratio } & \multirow[t]{2}{*}{ Sig. } \\
\hline & & $\mathrm{B}$ & Std. Error & & & \\
\hline \multirow{4}{*}{1} & (Constant) & .896 & .119 & & 7.513 & 0.000 \\
\hline & Interaction & .086 & .011 & .526 & 7.497 & 0.000 \\
\hline & Ethical Leadership & .388 & .066 & .411 & 5.858 & 0.000 \\
\hline & Conscientiousness & .870 & .049 & .802 & 17.889 & 0.000 \\
\hline
\end{tabular}

A multiple regression model was tested to examine if there is a moderation effect of conscientiousness on the relationship of ethical leadership on employee well-being, the value of F-statistics, which is 444.619 shows that the overall model is statistically significant at $95 \%$ confidence level, the value of R2 is .834 which shows $83 \%$ of the variance in employee well-being. The interaction between ethical leadership and employee conscientiousness was significant for employee well-being, while $(\beta=.388, \mathrm{SE}=.066, \mathrm{P}=.000)$ suggesting that the relationship between ethical leadership and employee well-being is moderated by conscientiousness. since the $\mathrm{P}$ value of moderating variable is less than $0.05(\mathrm{P}<0.05)$, that is $\mathrm{P}$-value is .000 , therefore we will reject the null hypothesis, and will conclude that there is a significant moderating effect of conscientiousness on the relationship of ethical leadership and employee wellbeing.

Table 8 Moderation Effect of Conscientiousness on the Relationship of Ethical Leadership and Employee Voice:

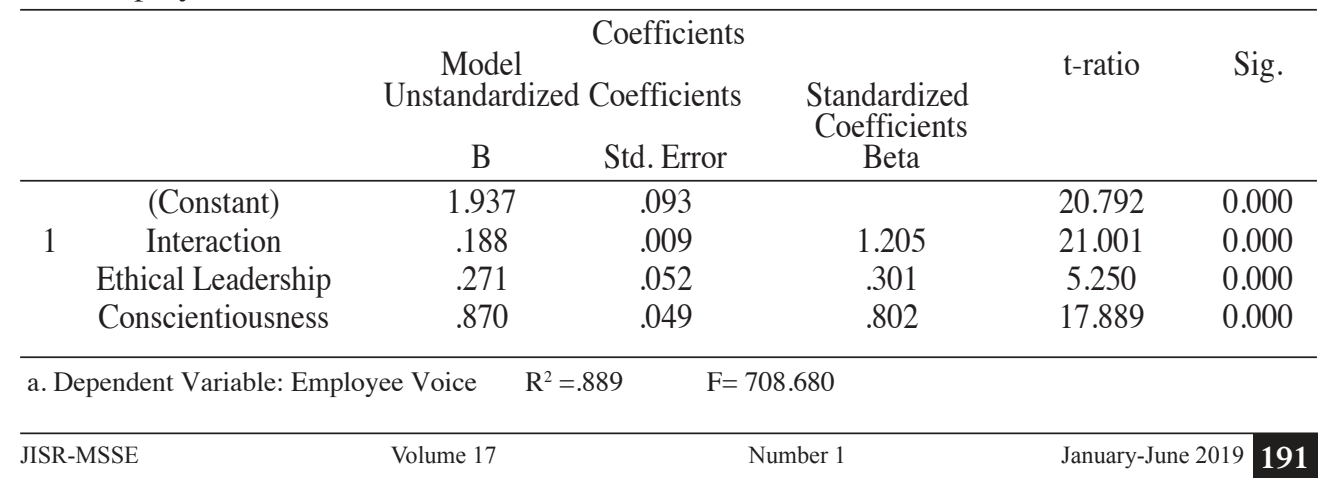


A multiple regression model was tested to explore whether there is a moderation effect of conscientiousness on the relationship of ethical leadership on employee voice, the value of F-statistics, which is 708.680 indicates that the overall model is statistically significant at $95 \%$ confidence level, the value of R2 is .889 which shows $88 \%$ of the variance in employee voice. The interaction between ethical leadership and employee conscientiousness was significant for employee well voice, while $(\beta=.271, \mathrm{SE}=.052, \mathrm{P}=.000)$ suggesting that the relationship between ethical leadership and employee voice is moderated by conscientiousness. since the $\mathrm{P}$ value of moderating variable is less than $0.05(\mathrm{P}<0.05)$, that is $\mathrm{P}$-value is .000 , therefore we will reject the null hypothesis, and will conclude that there is a significant moderating effect of conscientiousness on the relationship of ethical leadership and employee voice.

\section{DISCUSSION AND CONCLUSIONS}

The main purpose of this study was to find out the effect of Ethical leadership on employee work outcomes and also to explore how conscientiousness moderates this relationship. Convenient/Random sampling was used as a sampling technique and data was gathered from Non-Governmental organizations of Peshawar namely Khwendo kor, Kher Khegara Tanzeem, Pakistan Red Crescent Society, International Rescue Committee, Community Development Unit, and PADO. Data were tested and analyzed to find out mean, frequencies, demographics, reliability and regression analysis. For testing of the moderating effect of conscientiousness, Baron and Kenny (1986) four steps model was followed and hypotheses were tested. Findings of the study showed a significant relationship between Ethical leadership, Employee well-being, and Employee Voice. So, we accepted hypothesis No.1 (ethical leadership significantly affects Employee well-being) and hypothesis No.2 (ethical leadership significantly affects employee voice) and concluded that positive relationship exists between ethical leadership and job outcomes i.e. employee well-being and employee voice.

Similarly, findings of the study showed moderation of conscientiousness in the relationship of Ethical leadership with Employee well-being and Employee voice. It was concluded that conscientiousness moderates the relationship between ethical leadership employee well-being and employee voice which were tested and significantly moderated the relationship of ethical leadership with job outcomes i.e. employee well-being and employee voice). The contribution of this study to the literature was in the findings of the relationship between Ethical leadership and job outcomes i.e. employee well-being and employee voice along with the moderating effect of conscientiousness.

Leadership is said to be one of the core focus of HRM that directly influences the overall internal system. A strong and effective leadership tends to be one where leaders work together with the team and focus on bringing positivity within individuals by following norms and values. Hence, a leadership role for the organization tends to be learning-based because it is one of the initial sources for employees to follow organizational values. The focus of the study was towards exploring what ethical leadership is and how it influences employee work-related outcomes. The study focused on forming the relationship between ethical leadership and employee work outcomes based on the moderating role of conscientiousness. In the study, it was analyzed that when the leader focuses on promoting norms and values of the organization, then employees tend to be more participative. It makes employees responsible to perform their duties and increases their engagement in achieving their job-based targets. However, poor leadership increases absenteeism, poor employee wellbeing and poor conscientiousness (Brown \& Trevino, 2006).

192 January-June $2019 \quad$ Volume $17 \quad$ Number $1 \quad$ JISR-MSSE


In the literature review, it was discovered that leaders have their persona, which influences employees within the organization. If a leader manages to enhance its working abilities based on ethical practices, then it eventually makes employees responsible and careful towards their job-related outcomes. A direction given by the leader is the main source of motivation for employees towards their work (Schwepker, 2015). In this regard, Givens (2008) discussed that when a leader tends to focus on moral values, then as a result, it is seen in their decision-making and problem-solving. By maintaining ethically based focus on decision making, a leader can help the organization to maintain its competitive advantage. Moreover, organizations that have ethical leaders tend to have more strong HR systems. Such systems focus on justified methods of incentives, promotions, and compensations. Such type of leadership also helps employees to translate appropriate and clear meanings of goals and objectives assigned to them. It fosters employees to work on such grounds where they can show true loyalty and commitment towards the organization. Further, it was also discussed in the literature review that ethical leaders are the main source of incorporating moral values and principles in organizational decision-making. Such leadership encourages fairness and equality within the organization.

Based on this focus, the investigation was done in the study in order to explore the impact that ethical leadership creates on employee work-related outcomes such as employee voice, employee wellbeing, and conscientiousness as moderating role. The objectives of the study were specific towards examining the influence of ethical leadership on job-related outcomes and explore the level of relationship with the outcomes of the job. Based on this, 3 major factors were investigated as the outcome of the job, which include employee voice, employee wellbeing, and conscientiousness. The first objectives were based on investigating the influence of ethical leadership on these 3 factors. Hence, to achieve this objective, several arguments and secondary information were presented in the literature review. The hypotheses of the study were specific to examine the significant impact of ethical leadership on employee voice, employee well-being and conscientiousness (Derr, 2012). To test the hypotheses, regression analysis and correlation matrix were obtained. Based on the first objective, the literature review proposed several arguments and theoretical perspective. It was identified that leadership influence is direct on employees. Good leadership results in employee engagement, satisfaction towards job and employee well-being. This eventually results in employee retention and turnout. Good and ethical leadership also encourages conscientiousness in employees because this helps in increasing employee well-being. Employee delicacy is the result of their commitment and dedication to perform well in the organization. Hence, an ethical leadership within the organization creates balance in the internal system and gives true guidance to its employees that not only leads to their career development, but also create balance in their lives (Abrheim, 2012). In view of the contentions presented in the literature review, the primary target of the study was accomplished.

The second target of the study depended on examining the relationship among variables based on the hypotheses designed. Hence, in light of the discoveries of the study, it can be inferred that the alternative hypotheses of the study were accepted. There is a significant relationship found among ethical leadership, employee voice, employee well-being, and conscientiousness. From the analysis and results obtained, it was identified that the following variables had a significant impact. The independent variable for the study was ethical leadership, whereas the dependent variables were employee voice, employee well-being, and conscientiousness. From the results and analysis conducted, it was identified that employees

\begin{tabular}{llll}
\hline JISR-MSSE & Volume 17 & Number 1 & January-June 2019 \\
\hline
\end{tabular}


consider ethical leadership as an essential tool for their career growth because if employees are trained under the supervision of an ethical leader, then they are able to develop strong skills in them (Ahmad \& Muchiri, 2013). Moreover, this also increases moral values in employees and helps them to create balance in their lives that leads to a positive outcome at the job (Derr, 2012). The findings of the study also helped in concluding that the objectives of the study are linked to the literature review, and thus by designing the framework based on the theoretical perspective, the results were also aligned to the objectives.

Based on the gathered data and findings obtained, it can be established that there is strong of ethical leadership with employee work outcomes and the role of conscientiousness is moderating in the relationship. The employee related outcomes discovered in the study were employee voice, employee well-being, and job-related factors. Hence, from the gathered data, it was identified that the job-related outcomes are merely based on good management. However, good management can only be seen when there is good leadership. Based on these outcomes, it can be concluded that ethical leadership is essential for organizations because it helps them to maintain their internal harmony and employee engagement towards achieving organizational goals.

\section{REFERENCES}

Abrheim, T. (2012). Ethical Leadership: Keeping Values in Business Cultures, Business and Management Review, 2(7): 11-19.

Ahmad, E. \& Muchiri, M. (2013). Effects of Psychological Contract Breach, Ethical Leadership and Supervisor's Fairness on Employee's Performance and Well-Being, Proceedings of 23rd International Business Research Conference: 1-13.

Akker, L., Heres, L., Lastuizen, K., \& Six, F. (2009). Ethical Leadership and Trust: It's All About Meeting Expectations, International Journal of Leadership Studies, 5(2): 102-124 Aron, (2007). Statistics for Psychology. India: Pearson Education.

Avey, J. B., Wernsing, T. S., \& Palanski, M. E. (2012). Exploring the Process of Ethical Leadership: The Mediating Role of Employee Voice and Psychological Ownership. Journal of Business Ethics, 107(1), 21-34.doi:10.1007/s10551-012-1298-2

Babalola, M. T., Stouten, J., Euwema, M. C., \& Ovadje, F. (2016). The Relation Between Ethical Leadership and Workplace Conflicts: The Mediating Role of Employee Resolution Efficacy. Journal of Management, 44(5), 2037-2063. doi:10.1177/0149206316638163

Babalola, M. T., Bligh, M. C., Ogunfowora, B., Guo, L., \& Garba, O. A. (2019). The mind is willing, but the situation constraints: why and when leader conscientiousness relates to ethical leadership. Journal of Business Ethics, 155(1), 75-89.

Barkhordari-Sharifabad, M., Ashktorab, T., \& Atashzadeh-Shoorideh, F. (2017). Ethical leadership outcomes in nursing. Nursing Ethics, 25(8): 1051-1063 doi:10.1177/0969733016687157

Bavik, Y. L., Tang, P. M., Shao, R., \& Lam, L. W. (2018). Ethical leadership and employee knowledge sharing: Exploring dual-mediation paths. The Leadership Quarterly, 29(2), 322-332. doi:10.1016/j.leaqua.2017.05.006

Blau, P. M. (1964). Exchange and power in social life. New York: Academic Press

Brown, M. \& Trevino, L. (2006). Ethical Leadership: A Review and Future Directions, The Leadership Quarterly, 17(2): 595-616. 
Burris, E. R. (2012). The Risks and Rewards of Speaking Up: Managerial Responses to Employee Voice. Academy of Management Journal, 55(4), 851-875. doi:10.5465/amj.2010.0562.

Chughtai, A., Byrne, M. \& Flood, B., (2015). Linking ethical leadership to employee well-being: The role of trust in supervisor, Journal of Business Ethics, 128(3), pp.653-663.

Derr, C. (2012). Ethics and leadership, Journal of Leadership, Accountability, and Ethics, 9(6): 1-16.

Fehr, R., Yam, K.C.S. \& Dang, C., (2015). Moralized leadership: The construction and consequences of ethical leader perceptions, Academy of Management Review, 40(2), pp.182-209.

Givens, R. (2008). Transformational Leadership: The Impact of Organizational and Personal Outcomes, Emerging Leadership Journeys, 1(1): 4-24.

Gravetter, F.J., and Forzano, L.B. (2011). Research Methods for the Behavioural Sciences. $4^{\text {th }}$ ed. Cengage Learning.

Greco, L. M., Whitson, J. A., O'Boyle, E. H., Wang, C. S., \& Kim, J. (2019). An Eye for an Eye? A Meta-Analysis of Negative Reciprocity in Organizations. Journal of Applied Psychology. https://doi.org/10.1037/ap10000396

Hazy, J. (2008). Towards a Theory of Leadership in Complex Systems: Computational Modeling Explorations, Non-Linear Dynamics, Psychology and Life Sciences, 12(3), 281-310.

Haybron, D. M. (2000). Two philosophical problems in the study of happiness. The Journal of Happiness Studies, 1, 207 - 225.

Hoch, J. E., Bommer, W. H., Dulebohn, J. H., \& Wu, D. (2018). Do Ethical, Authentic, and Servant Leadership Explain Variance Above and Beyond Transformational Leadership? A Meta-Analysis. Journal of Management, 44(2), 501-529. https://doi.org/10.1177/0149206316665461

Hofmann, D. A., \& Jones, L. M. (2005). Collective personality and performance. Journal of Applied Psychology, 90, 509-522.

Ilies, R., Morgeson, F. P., \& Nahrgang, J. D. (2005). Authentic leadership and eudaemonic well-being: Understanding leader-follower outcomes. The Leadership Quarterly, 16(3), 373-394. doi:10.1016/j.leaqua.2005.03.002

Jeremy. M, Melinde .C \& Ciller V. (2012). Perceived leadership style and employee participation in a manufacturing company in the democratic republic of Congo, African Journal of Bbusiness Management, .6(15), 5389-5398.

Kaptein, M. (2019). The moral entrepreneur: A new component of ethical leadership. Journal of Business Ethics, 156(4), 1135-1150.

Keegan, S. (2009). Qualitative Research: Good Decision Making Through Understanding People, Cultures and Markets. Kogan Page Publishers.

King, N. and Horrocks, C. (2010). Interview in Qualitative Research. SAGE.

Kremer, H., Villamor, I., \& Aguinis, H. (2019). Innovation leadership: Best-practice recommendations for promoting employee creativity, voice, and knowledge sharing. Business Horizons, 62(1), 65-74.

Kumar, R. (2011). Research Methodology. APH Publishing 
Lee, D., Choi, Y., Youn, S., \& Chun, J. U. (2015). Ethical Leadership and Employee Moral Voice: The Mediating Role of Moral Efficacy and the Moderating Role of Leader-Follower Value Congruence. Journal of Business Ethics, 141(1), 47-57.doi:10.1007/s10551-015-2689-y

LePine, J. A., \& Van Dyne, L. (1998). Predicting voice behavior in work groups. Journal of applied psychology, 83(6), 853.

Luu, T. T. (2019). The well-being among hospitability employees with disabilities: The role of disability-inclusive benevolent leadership. International Journal of Hospitality Management, 80, 25-35.

Mehilic, K., Lipicnik, B., \&Tekavcic, M. (2010). Ethical Leadership, International Journal of Management and Information Systems.14(5): 31-52.

Mo, S., Ling, C.-D., \& Xie, X.-Y. (2017). The Curvilinear Relationship Between Ethical Leadership and Team Creativity: The Moderating Role of Team Faultlines. Journal of Business Ethics. doi:10.1007/s10551-016-3430-1

Mo, S., \& Shi, J. (2016). The Voice Link: A Moderated Mediation Model of How Ethical Leadership Affects Individual Task Performance. Journal of Business Ethics. doi:10.1007/s10551-016-3332-2

Ojokuku, R.M., Odetayo, T.A. \& Sajuyigbe, A.S. (2012). Impact of Leadership Style on Organizational Performance: A Case Study of Nigerian Banks, American Journal of Business and Management, Vol. 1, No. 4, pp. 202-207.

Peng, H., \& Wei, F. (2019). How and When Does Leader Behavioral Integrity Influence Employee Voice? The Roles of Team Independence Climate and Corporate Ethical Values. Journal of Business Ethics, 1-17.).

Ritch, S. \& Mengel, T. (2009). Guiding Questions: Guidelines for Leadership Education Programs, Journal of Leadership Education, 8(1): 216-225.

Schwepker Jr, C.H., (2015). Influencing the sales force through perceived ethical leadership: the role of sales force socialization and person-organization fit on salesperson ethics and performance, Journal of Personal Selling \& Sales Management, 35(4), pp.292-313.

Smircich, L., \& Morgan, G. (1982). Leadership: The management of meaning. The Journal of Applied Behavioral Science, 18(3), 257-273.

Walumbwa, F. O., Morrison, E. W., \& Christensen, A. L. (2012). Ethical leadership and group in-role performance: The mediating roles of group conscientiousness and group voice. The Leadership Quarterly, 23(5), 953-964.doi:10.1016/j.leaqua.2012.06.004

Walumbwa, F., Mayer, D., Wang, P., Wang, H., Workman, K., \& Christensen, A. (2011). Linking ethical leadership to employee performance: The roles of leader-member exchange, self-efficacy, and organizational identification, Organizational Behavior and Human Decision Process, 115(1): 204-213.

Watson, T. (2010). Leader Ethics and Organizational Commitment, ULR Journal, 3(1): 16-25.

Western, S. (2019). Leadership: A critical text. SAGE Publications Limited. doi: $10.4135 / 9781446280294$

Xhang, X., Walumbwa, F., Aryee, S., \& Chen, Z. (2013). Ethical Leadership, Employee Citizenship, and Work Withdrawal Behaviors: Examining Mediating and Moderating Process, The Leadership Quarterly, 24(2): 284-297.

Zhang, S., \& Tu, Y. (2016). Cross-Domain Effects of Ethical Leadership on Employee Family and Life Satisfaction: the Moderating Role of Family-Supportive Supervisor Behaviors. Journal of Business Ethics. doi:10.1007/s10551-016-3306-4 